\title{
Implementation Analysis of Curriculum 2013 Towards Interactive Learning Aspects and Multimedia-Based Learning
}

\author{
Diah Ayu Lestari, Sutrisno \\ Departement of Management, Universitas Negeri Malang \\ Email: diahayu1785@gmail.com
}

\begin{abstract}
This research aims to determine the application of interactive and multimedia-based learning which conducted by the teachers from office administration in state vocational high school 2 Blitar. This research is qualitative research then the subjects are the teachers' expertise of administrative programs, vice principal of curriculum and students. Data collection techniques used observation, interviews, and documentation. The results of this research are (1) interactive learning have been implemented, (2) Multimedia-Based learning has been implemented, but it is needed for developing the multimedia which used for teaching process. It can be seen that the teacher conducts learning in accordance with interactive learning indicators. The implementation of the curriculum 2013 for aspects of multimedia-based learning has been carried out by teachers by implementing learning that contains multimedia-based learning indicators.
\end{abstract}

Keywords: curriculum 2013, interactive learning, multimedia-based learning

\section{INTRODUCTION}

The importance of education has been concerned for citizen throughout the world (Kuyumcu, 2012). One of them is Indonesia, a country where some it's people have considered education is very important. However, according to Munastiwi (2015), the quality of education output in Indonesia is still low compared to some countries in ASEAN region even Asia. The inadequate quality of education requires comprehensive handling owing to the fact that education plays an important role. One of the efforts that has been made by the government in Indonesia is curriculum development to achieve national goals. Currently the applied curriculum is known as the curriculum 2013. Teacher's readiness in the implementation of this curriculum has increased. It can be shown from the teacher's readiness in preparing the Lesson Plan and conducting learning activities, as well as implementing learning assessments that in accordance with the curriculum 2013.

The development of curriculum 2013 keep continues to be endeavored, considering many challenges in globalization era. Internal obstacles related to the Indonesian citizen development that can be seen from the growth of the productive age population. While external challenges refer to globalization era including environmental issues, advances in information technology, convergence of science and technology, knowledge-based economics, the rise of creative and cultural industries, fractioning of world economic power, technology influence and impact, investment quality and transformation in the sector of education (Munastiwi, 2015). Therefore, curriculum development is based on Republic of Indonesia Minister of Education and Culture regulation number 70 year 2013 regarding the basic framework and structure of the state or madrasa $h$ vocational high school curriculum which stated that the Curriculum 2013 was developed by improving the mindset to create a learning process centered on students so that it can interactively proceed, 
open networking, more active and critical because the knowledge that has been obtained is plural, and multimedia-based.

State vocational high school 2 Blitar has implemented the Curriculum 2013 since 2015. As the result of development, that school has followed and implemented the improvement of mindset which consisting of 9 patterns contained in Ministry of Education and Culture No. 70 year 2013. While in the learning process the teachers must involve students in the learning process so that it will appropriate with curriculum 2013 that students are sued to be active in learning activities. in addition, the media used has been changed from the board to projector screen, where the teacher is required to use the media provided in each class. based on that statement, this research focus on interactive learning and multimedia-based learning.

Interactive learning is a learning process that allows active students to engage themselves in learning process Oprea (2014), both mentally and physically. The role of students in interactive learning is assumed as important in spite of the fact that the learning approach is centered on students and the teacher is only as a facilitator to embody learning process that aim to active activities for students. Interactive learning is designed to make students learning focus on the students in order to they are able to active develop their knowledge through the inquiry of the questions submitted (Walters et al., 2017). Therefore, students are given the full opportunity to involve their curiosity. The application of interactive learning has characteristics such as 1) there are variations in classical activities, groups, and individuals, 2) mental involvement (thoughts and feelings) of high students, 3) teachers act as facilitators, resource persons, and democratic class managers, 4) implement many ways of communication patterns, 5) a flexible, democratic, challenging class and still controlled by the objective, 6) the potential for more effective accompaniment impacts.

In the learning process the teacher must be able to understand the nature of the material to be taught as a lesson that can develop students' thinking skills. In addition to mastering the material, the teacher must also make a classroom atmosphere that supports interactive learning. The class atmosphere that occurs can be seen from the extent to which the teacher gives the opportunity to practice, show encouragement and attention, build cooperation or competition, and provide freedom of opinion and choice (Gröschner et al., 2018). Another thing that teachers need to do is understand various learning models that can stimulate the ability of students to learn, which is well-prepared teaching planning by the teacher to create interactive learning. Interactive learning can be created by applying interactive learning model. There are many interactive learning models that can be applied by teachers in teaching and learning process Oprea (2014) including 1) jigsaw, 2) student teams-achievement division (STAD), 3) number head together, 4) think pair and share, 5) debate, 6) role playing, 7) Group Investigation, 8) talking stick, 9) snowball throwing, 10) demonstration, 11) Articulation, 12) Problem Based Introduction (PBI), and 13) mind mapping.

Interactive learning is the interaction between teachers and students and between students with students is multi-purpose communication. So to embody this, the teachers have to choose a fun strategy. Which states that things that are fun can explore and develop the motivation of students (Gutiérrez \& Tomás, 
2018). Learning motivation is an important factor in the learning process because it belongs to the determinant components that produce quality of learning of students. Therefore, there is a need for teacher actions related to motivation in the learning process. Strategies that can be conducted by teachers to increase motivation are 1) giving numbers, 2) giving gifts, 3) rivals or competitions, 4) egoinvolvement, 5) giving tests, 6) knowing the results because it can encourage students to be more diligent in learning process, 7) giving praise, 8) punishment, 9) developing desire to learn, 10) interest, 11) recognized goals (Gutiérrez \& Tomás, 2018).

Furthermore, the achievement of the application of interactive learning in learning is not emphasized on the results but on the learning process (Rodríguez et al., 2018). Thus, the implementation of interactive learning activities need to formulate learning strategies that lead students to be able to gain knowledge by being involved and experiencing as well as not by memorizing ways. The implementation of interactive learning has advantages, one of that is learning results are more meaningful (Kostiainen et al., 2018). Learning activities will develop rapidly with multimedia assistance (Mayer, 2014). Multimedia is a combination of various types of digital media such as text, images, sounds and videos that are integrated in multisensory apps or interactive presentations to deliver a message or information on the viewers (Mayer, 2014; Soruç, 2015). If the two concepts are combined, multimedia-based learning is a learning process that uses media that is text, images, sounds, and videos in teaching and learning process. Multimedia can be applied and will be important role in the field of education, especially in the learning process. Multimedia learning has characteristics that can be used by the teacher as a guide, such as 1) contains the material of representative material of visual, audio, and audiovisual, 2) various communication media in it's usage, 3) varied types of learning, 4) learning response and varies of reinforcement, 5 ) can be used classically or individually, 6) can be used offline or online.

Before get into the technological era in education especially in learning process, multimedia was known as a form in integrating various elements of printed learning media, audio cassettes, and sound slides. Media elements are combined and used to deliver learning material because of the assumption that each media that is utilized has strengths and weaknesses. so, utilization is conducted in combination to get complementary media in accordance with learning outcomes. The variation of media used by teachers can help students to strengthen understanding and smooth learning in achieving their goals (Paratore et al., 2016). Currently education has been intervened by the existence of technology so that applied learning experiences progress from traditional learning to the usage of information and communication technology. In the transformation of the message in learning process there is a change in proportion to the development of information and communication technology that creates internet media. In real terms the Internet can be used as a medium in the learning process because internet is a multi-media visual means to the internet can be used to communicate interpersonal and communication can be used to perform more than one person. In conclusion, the use of multimedia can be conducted offline and online. In line with these statements learning with online multimedia is teaching which in the learning process is connected with telecommunications networks such as the internet and 
offline multimedia is teaching like conventional or traditional (Mayer, 2014; Soruç, 2015)

As a result, the use of multimedia in the learning process needs to be sorted according to learning component. In general, the use of multimedia can be applied by teachers in a classical or individual way to their teaching strategies. Classical learning is learning that sees students with the same ability and then students get lessons together, in the same way, and in one class and individual learning is a teaching and learning activity that focuses on assistance and guidance to each student. While related to multimedia-based learning strategies by utilizing multimedia in the learning process can apply learning models using multimedia in the form of drill and practice models, tutorials, games, simulations, discovery, and problem solving. The benefits obtained by implementing multimedia-based learning are the creation of interactive, fun, more interesting learning, facilitating students' understanding, and improving the quality of learning. This is because multimedia can develop sensory abilities and attract attention and interest. Therefore, the attention and interest of students during the learning process is one form of students' response to multimedia-based learning. Responding to this, so that the students always respond interrupted ma teacher learning process should provide feedback such as by providing a positive response will motivate children to maintain the achievements, and even improve performance (Pahljina-Reinić and Kolić-Vehovec, 2017).

\section{METHOD}

This study uses a qualitative approach. Qualitative research is research that tries to understand phenomena in their natural settings and contexts. The purpose of this qualitative research is to describe the proven reality behind the phenomenon in depth and detail. This type of research is a case study. Case study research is a study that explores a problem with detailed limits, in-depth data collection, and includes various sources of information. This type of research is limited by the time, place and case studied. This research will be conducted to the application of the curriculum 2013 in the aspect of interactive learning and multimedia-based learning. The main data sources in this study are the words and actions of the people interviewed or observed. The main data source can be accomplished by recording videos or taking photos. The subjects in this study were teachers of the Office Administration Expertise Program, Deputy Principals in the curriculum, and students at Blitar 2 State Vocational School. Retrieval of data in this study was also carried out through interviews, observation, and documentation.

Based on the data obtained by a researcher, the process of data analysis begins by examining all available data from various sources, namely observation, interviews, documents. The various data are read, studied, and reviewed, then the data reduction step is carried out by making core summaries, processes, and statements classified and filtered, but the resulting data is still natural. Then the next step is the presentation of some information that is composed of an analysis of the implementation of the curriculum 2013 towards interactive and multimedia-based learning aspects. Data that has been reduced and arranged in the form of a study is 
then concluded by the researcher and related with focus of the research in this study. The last stage of data analysis is to hold data validity.

This research establishes the validity of the data using triangulation examination techniques. The data triangulation used was source triangulation and triangulation with techniques. Triangulation of sources means to get data from different sources with the same technique while triangulation technique means that researchers use different data collection techniques to get data from the same source.

\section{RESULTS \& DISCUSSION Results}

Curriculum 2013 was developed by improving mindset one of which is one-way learning into interactive learning listed in Permendikbud No 70 of 2013. The learning process can be categorized as interactive learning, namely in the learning process, including indicators 1) there are variations in classical activities, groups, and individuals, 2) mental involvement (thoughts and feelings) of students, 3) teachers act as facilitators, resource persons, and democratic class managers, 4) apply many-way communication patterns, 5) a flexible, democratic, challenging and permanent classroom atmosphere controlled by purpose, 6) the potential for more effective escort effect can be produced. Teachers of office administration skills program at state vocational high school 2 Blitar carry out interactive learning seen from the learning process which has a variety of classical, group and individual activities.

This can be seen from the learning strategies applied. The strategy applied by the teacher is shown in classical learning activities, groups, and individuals. Classical activities are applied in lecture activities by explaining the material. Group activities are implemented with group learning that conducts discussion activities in the learning process. While individual activities are shown in the activities of the teacher who applies the task method by giving assignments to students. Other findings in this study are weaknesses in the application of learning strategies that have not been optimal in general administration introductory subjects, for instance students still do not understand the tasks given by the teacher at the previous meeting, so that not all students work on the task and consequently the discussion is postponed. Solutions to these problems from teacher is explains the material related to a given task and then proceed with the assignment of ending the discussion. There are variations in classical activities, groups, and individuals in learning strategies capable of activating students. Related to this, in interactive learning the teacher has a role to activate students in learning, especially in skills development (Rodríguez et al., 2018).

Interactive learning is a learning process that allows active students to engage themselves in the learning process, both mentally and physically (Hossain et al., 2017; Rodríguez et al., 2018; Walters et al., 2017). Therefore, to implement interactive learning the teacher must involve students during learning. Teachers engage students mentally in learning materialized in teacher activities to foster curiosity and explore students' initial knowledge. The teacher's efforts to foster curiosity of students is conducted by applying the question and answer method and 
providing problems or assignments to explore the material to be studied. Other efforts made by teachers to engage students mentally are by exploring students' initial knowledge. Exploring the initial knowledge is conducted by the teacher by applying the method of asking and reviewing the material that has been studied at the previous meeting. The use of the question and answer method used by teachers in learning is able to foster interactive learning. The teaching and learning process that interactive teachers can develop effective questioning techniques or engage in creative dialogue by asking questions to students.

The question and answer method were also applied by the teacher to implement multiple-way communication. Besides that, it also applies lecture methods, assignment methods, and discussion methods as actions to foster multiple-way communication during the learning process. The application of lecture and question and answer methods conducted by the teacher can foster interaction between teachers and students. In addition, the teacher also applies discussion and assignment methods to foster interaction between students and other students and students with learning resources. Learning that is done with a variety of teaching methods can create interaction patterns. The optimal pattern of interaction between teachers and students, students and teachers, and between students and students is a multi-purpose communication that is in accordance with the concepts of active students (Hossain et al., 2017).

\section{Discussion}

Interactive learning means that teaching is not only delivering knowledge from the teacher to students but teaching is also considered as a process of regulating the environment that can stimulate students to learn and achieve learning goals. A flexible, democratic, challenging classroom atmosphere and controlled learning by objectives is carried out by applying learning models adapted to the material. The learning model applied by the teacher's office administration expertise program includes cooperative learning, numbered head together, discovery learning, think pair and share, problem solving of problem based learning. The learning model can be categorized in an interactive learning model.

Other actions taken by the teacher to foster a flexible, democratic, challenging and still controlled classroom atmosphere with the aim of giving the teacher the flexibility for students to argue, cooperation and provide opportunities for students to play a role in learning process. The effort made by the teacher to create a classroom atmosphere in learning process of the classroom atmosphere that occurs can be seen from the extent to which the teacher gives the opportunity to practice, show encouragement and attention, build cooperation or competition, and provide freedom of opinion and choice. Other findings the teacher concentrates the attention of students during the learning process. The attention of students can make students active during the learning process. The teacher's actions in this finding are applying a method of asking questions to focus students' attention during learning.

Interactive learning is also influenced by the role of the teacher as a facilitator, resource person, and class manager. As a facilitator and teacher resource office administration expertise program at state vocational high school 2 Blitar 
provides material from a variety of customized sources and provides media as a tool to deliver material to students. As a classroom manager the teacher must also pay attention to the situation of students during learning. Related to this, the teacher provides learning motivation to students so that interactive learning occurs. Motivation given by the teacher which is seen in activities once the teacher gives questions to the less enthusiastic students, gives a review related to the benefits of what is learned in the learning process, and conveys any judgments that are assessed especially the activity of students so that students are motivated and active.

The results of the application of interactive learning will have an impact on teachers and students. For teachers the impact of learning is in results that can be measured as and the learning outcomes of students in the values or numbers. While for students the effect of accompaniment is the application of knowledge or abilities in a particular field as a transfer of learning that reaches independence. The results achieved by students in understanding can be classified as good, and overall the original values obtained by students have been completed, but only a few students in the less category. Meanwhile the impact of accompaniment for students related to the independence of students is still not optimal because of the need for the role of teacher as a facilitator in the learning process. It can be concluded that the office administration skills program teacher has implemented interactive learning that can be seen from the implementation of learning, namely 1) there are variations in classical activities, groups, and individuals, 2) involving mental learners, 3) applying many-way communication patterns, 4) there is a class atmosphere flexible, democratic, challenging, and kept under control by purpose, 5) there is the role of the teacher as a facilitator, resource person, and democratic class management, 6) the potential to produce more effective accompaniment impacts.

Multimedia-based learning is defined as a learning process that uses media in the form of text, images, sounds, and videos in the teaching and learning process. Teacher learning can be said to be multimedia-based learning if it contains several indicators, namely 1) containing representative material content in visual, audio, and audiovisual, 2) various communication media and their uses, 3) varied types of learning, 4) learning and reinforcement responses vary, 5) can be used classically or individually, 6) can be used offline and online. Multimedia-based learning is applied by the teacher's office administration skills program conducted with the usage of power points. In addition, the use of various communication media also involves teachers, namely using books, Microsoft Word, power point action, internet, e-modules, and several media in multimedia forms that are tailored to the material. The internet can be used as a medium in the learning process. The various media used by the teacher, the results of that the variety of media used by teachers can help students to strengthen understanding and smooth learning to achieve goals.

The application of multimedia-based learning in the delivery of material in the form of power point does not only move text into the media, but also is selected. This means that the material must be representative to be made power point in the learning process. The teacher's power point contains representative material in visual form. It means that the teacher makes a power point that contains material in text and collaborates with appropriate images hence it will suitable for 
material and multimedia in visual form. Sometimes the teacher also uses power point action containing material adapted and used by the video related to the material that make the material and multimedia suitability in audiovisual form are appropriate. The conclusion in the application of multimedia-based learning is that teachers use media that contains representative material content in visual and audiovisual forms.

The teachers use power point as a multimedia form that is applied in classical learning in the classroom during class time. Classical learning is learning that sees students with similar abilities that make students get lessons together, in the same way, and in one class. The teacher also conducts individual learning as the application of multimedia-based learning. Individual learning is a teaching and learning activity that focuses on help and guidance for each student. Individual learning is used by teachers in providing material that has been compiled and given to students in the form of hands out and the sharing of learning resources through the Whatsapp for example which students can learn independently. Teachers apply multimedia classically and individually in multimedia-based learning to suit the needs of students during learning.

The application of multimedia-based learning by teachers is conducted offline and online. Offline multimedia in using power points of the learning process. while multimedia online is also used by teachers by using the internet in the learning process. The teacher uses multimedia offline and online in accordance with the type of multimedia, namely multimedia can be online and offline. The implementation of multimedia-based learning contains varied types of learning. Different types of learning can be conducted by the teacher by using various learning models and learning methods that use media in the teaching process as a tool and source of learning in learning strategies.

Teachers applying multimedia in their learning strategies are carried out using demonstration learning models, discovery, think pair and share, problem solving, and problem based learning with methods of lecture, discussion, and assignment and using power point as one of the media to deliver material. The model applied by the teacher is a learning model that can use multimedia (Mayer, 2014) learning models using multimedia can be drill and practice models, tutorials, games, simulations, discovery, and problem solving. In addition, the teacher applies the preaching method in the form of the teacher's activities to explain the material with the help of power point and the method of discussion carried out by the students then presentations using power point. The assignment method is also applied by the teacher by giving assignments to search related material will be studied with the help of learning resources such as the internet. The assignment is also given by the teacher in a hand out for discussion. Therefore, multimedia-based learning conducted by teachers by applying learning models using media-assisted methods shows that the teacher still has a role and the media only helps to achieve learning objectives optimally.

The application of multimedia-based learning makes students respond that students feel motivated and happy. Subsequently, the responses given by students can also be seen in the activities of student's attention to slideshows and to the teacher's explanation in learning using power points. The presence of multimedia can attract the attention of students, therefore it arouses interest, motivation, 
activity, and learning creativity (Hossain et al., 2017; Mayer, 2014). Learning can reach its goals optimally with the feedback from teachers and students. In response that given by students, the teacher provides reinforcement as feedback. The form of reinforcement provided by the teacher is by giving students the opportunity to express their opinions and ask questions. Strengthening that given by the teacher is a positive response given as a form of feedback on students' responses during learning. With a positive response from teacher will motivate students to maintain achievement, even increase their achievements.

\section{CONCLUSION}

The application of the curriculum 2013 for interactive learning aspects published in the Minister of Education and Culture number 70 year 2013 was carried out by the teacher of the office administration expertise program at the state vocational school 2 Blitar. It can be seen that the teacher conducts learning in accordance with interactive learning indicators. The implementation of the curriculum 2013 for aspects of multimedia-based learning has been carried out by teachers by implementing learning that contains multimedia-based learning indicators. Based on the learning that conducted by the office administration program teachers in state vocational high school 2 Blitar related to the implementation of the curriculum 2013 the interactive learning aspects conducted by the teacher are appropriate but the teacher should develop the applied learning process, especially regarding learning strategies and assignments to students must be clear to achieve learning objectives and learning strategies optimally. Teachers should develop multimedia as a form of multimedia-based learning so that the multimedia that is used has already contained material in visual, audio, and audiovisual forms.

\section{REFERENCES}

Kuyumcu, F. N. 2012. The Importance of "Art Education" Courses in the Education of Prospective Teachers. Procedia - Social and Behavioral Sciences, The World Conference on Design, Arts and Education (DAE-2012), May 1-3 2012, Antalya, Turkey 51, 474-479. https://doi.org/10.1016/j.sbspro.2012.08.192

Ministry of Education and Culture. 2013. Republic of Indonesia Minister of Education and Culture Regulation No. 70 of 2013 concerning the Basic Framework and Structure of Vocational Middle School Curriculum/Madrasah Aliya Vocational. Jakarta: Ministry of Education and Culture (Indonesian Origin)

Gröschner, A., Schindler, A.-K., Holzberger, D., Alles, M., \& Seidel, T. 2018. How systematic video reflection in teacher professional development regarding classroom discourse contributes to teacher and student self-efficacy. International Journal of Educational Research 90, 223-233. https://doi.org/10.1016/j.ijer.2018.02.003 
Gutiérrez, M., \& Tomás, J.-M. 2018. Motivational Class Climate, Motivation and Academic Success in University Students. Revista de Psicodidáctica (English ed.) 23, 94-101. https://doi.org/10.1016/j.psicoe.2018.02.001

Hossain, H.M.S., Khan, M.A.A.H., \& Roy, N. 2017. Active learning enabled activity recognition. Pervasive and Mobile Computing, Special Issue IEEE International Conference on Pervasive Computing and Communications (PerCom) 2016 38, 312-330. https://doi.org/10.1016/j.pmcj.2016.08.017

Kostiainen, E., Ukskoski, T., Ruohotie-Lyhty, M., Kauppinen, M., Kainulainen, J., \& Mäkinen, T., 2018. Meaningful learning in teacher education. Teaching and Teacher Education 71, 66-77. https://doi.org/10.1016/j.tate.2017.12.009

Mayer, R.E. 2014. Incorporating motivation into multimedia learning. Learning and Instruction 29,

171-173. https://doi.org/10.1016/j.learninstruc.2013.04.003

Munastiwi, E. 2015. The Management Model of Vocational Education Quality Assurance Using 'Holistic Skills Education (Holsked).' Procedia - Social and Behavioral Sciences, The 4th World Congress on Technical Vocational Education and Training (4thWoCTVET), 5-6 December 2014, Universiti Tun Hussein Onn Malaysia, MALAYSIA 204, 218-230. https://doi.org/10.1016/j.sbspro.2015.08.144

Oprea, C.L. 2014. Interactive and Creative Learning of the Adults. Procedia - Social and Behavioral Sciences, The Fourth International Conference on Adult Education, Romania $2014 \quad 142, \quad 493-498$. https://doi.org/10.1016/j.sbspro.2014.07.654

Pahljina-Reinić, R., Kolić-Vehovec, S. 2017. Average personal goal pursuit profile and contextual achievement goals: Effects on students' motivation, achievement emotions, and achievement. Learning and Individual Differences 56, 167-174. https://doi.org/10.1016/j.lindif.2017.01.020

Paratore, J.R., O’Brien, L.M., Jiménez, L., Salinas, A., \& Ly, C. 2016. Engaging preservice teachers in integrated study and use of educational media and technology in teaching reading. Teaching and Teacher Education 59, 247-260. https://doi.org/10.1016/j.tate.2016.06.003

Rodríguez, M., Prada, A., Díaz, I., Gonzalez, E., \& González-Miquel, M., 2018. Active Learning of Process Control, in: Friedl, A., Klemeš, J.J., Radl, S., Varbanov, P.S., Wallek, T. (Eds.), Computer Aided Chemical Engineering, 28 European Symposium on Computer Aided Process Engineering. Elsevier, pp. 16931698. https://doi.org/10.1016/B978-0-444-64235-6.50295-3

Soruç, A., 2015. What Makes Redundant Presentation of Multimedia Learning Difficult? Procedia - Social and Behavioral Sciences, The Proceedings of 6th World Conference on educational Sciences 191, 2844-2848. https://doi.org/10.1016/j.sbspro.2015.04.402

Walters, B., Potetz, J., \& Fedesco, H.N., 2017. Simulations in the Classroom: An Innovative Active Learning Experience. Clinical Simulation in Nursing 13, 609-615. https://doi.org/10.1016/j.ecns.2017.07.009 